\title{
EDUCAÇÃO SUPERIOR: BEM PÚBLICO, EQUIDADE E DEMOCRATIZAÇÃO
}

\author{
José Dias SobrinHo*
} *Doutor em Educação pela Universidade Estadual de Campinas. Professor titular do programa de Pós-
graduação em Educação da Universidade de Sorocaba, SP, Brasil. E-mail: jose.sobrinho@prof.uniso.br

Resumo: A educação é um bem público, imprescindível e insubstituível, direito de todos e dever do Estado. É dever do Estado criar e oferecer condições efetivas para que isto se realize com a amplitude, a qualidade e a sustentabilidade necessárias e adequadas. Sendo bem público, a educação deve ser de qualidade. Esta é a base da discussão sobre democratização e políticas afirmativas. Por sua vez, a democratização e as políticas afirmativas da educação superior, como partes de um movimento muito mais amplo, impõem discutir um conceito de qualidade social, vinculado à pertinência, em contraposição a conceitos cientificistas e definições comprometidas com o mercado. Uma instituição educativa tem compromisso com o fortalecimento da democracia e deve ela mesma exercitar em seu cotidiano os conteúdos e formas da vida democrática. Não são muito precisos os limites do público e do privado, nem há consensos firmados sobre suas consequências na educação superior. Por isso é necessário discuti-los. De modo especial, importa examinar os limites e impactos da inclusão na educação superior de grupos tradicionalmente excluídos, em razão das escassas possibilidades de escolha de cursos de alto valor social e econômico, assim como as condições de permanência e de conclusão com qualidade e boas perspectivas de empregos. A inclusão desses grupos sociais vem acompanhada de sentimentos de ganhos e perdas. Cumpre uma essencial função social de incluir contingentes de indivíduos tradicionalmente excluídos, mas também pode estar contaminada por um fenômeno que pode ser chamado de "exclusão por dentro" do sistema educativo. Algumas das principais conclusões deste texto consistem em afirmar que a democratização da educação superior deve fazer parte da democratização da sociedade e da promoção da justiça social; não se restringe à ampliação do acesso, mas tem a ver com qualidade, pertinência e relevância social; além disso, a melhora da qualidade da educação superior está vinculada à ampliação e à elevação qualitativa de todo o sistema educativo e, mais amplamente, de transformações estruturais da sociedade. Portanto, é de responsabilidade coletiva.

Palavras-chave: Educação superior. Democratização. Pertinência. Inclusão/exclusão

\section{HIGHER EDUCATION: PUBLIC GOOD, EQUITY AND DEMOCRATIZATION}

Abstract: Education is a public good, indispensable and irreplaceable, a right of everyone and a duty of the State. It is the duty of the State to create and offer effective conditions to achieve this, with the essential and appropriate amplitude, quality and sustainability. As a public good, education must be of quality. This is the basis of discussion about democratization and affirmative policies. In turn, democratization and affirmative policies of higher education, as part of a much wider movement, impose the discussion of a concept of social quality, related to relevance, in opposition to scientific concepts and definitions committed to market. An educational institution is committed to the strengthening of democracy and must practice daily the contents and forms of democratic life. The limits of the public and private realms are not very precise and there is no established consensus about their consequences in higher education. Therefore it is necessary that they be discussed. In a special way, it is important to examine the limits and impacts of inclusion in higher education of traditionally excluded groups, due to very few possibilities of choice of programs with high social and economic value, as well as conditions of permanence, conclusion with quality and good employment prospects. The inclusion of these groups is accompanied by feelings of gains and losses. It serves an essential social function of including contingents of people traditionally excluded, but also it can be contaminated by a phenomenon that can be named "exclusion into" the education system. Some of the main conclusion of this text is to affirm that democratization 
of higher education must be part of the democratization of society and the promotion of social justice; it is not restricted to the increase of access, but it also relates to quality, pertinence and social relevance; in addiction, quality improvement of higher education is linked to qualitative increase of the education system as a whole and, more widely, to the structural transformation of society. It is, therefore, a collective responsibility.

Key words: Higher education. Democratization. Relevance. Inclusion/exclusion.

\section{INTRODUÇÃO}

A democratização da educação adquiriu centralidade na agenda das políticas públicas dos Estados, nos programas dos organismos multilaterais e nos movimentos sociais de diferentes matizes e de distintas partes do mundo. A meta mais relevante dessa agenda é a expansão da escolaridade da população em geral. Desde meados do século passado, a teoria do capital humano e a teoria residual do desenvolvimento postulavam a importância da educação como fator decisivo do desenvolvimento econômico. As visões atuais da democratização da educação em termos da expansão da escolarização, desde a superação do analfabetismo até o acesso aos mais elevados níveis superiores de ensino e pesquisa, também conferem à educação a importante função de motorizar a economia.

Estado e mercado tendem atualmente a se identificar no essencial a respeito das demandas e induções da funcionalização econômica da educação e impõem um conceito instrumental à democratização. Se levado às últimas conseqüências, o mercado que busca a qualquer preço impor sua primazia à sociedade global não se peja em descartar, por inúteis e imperfeitos, os indivíduos com baixa capacidade de produzir e de consumir. Para o mercado, quanto mais gente escolarizada, resguardados os limites e graus coerentes com a organização do mundo econômico, melhor para a produção e para o consumo.

A economia capitalista globalizada, ao organizar a sociedade mundial, determina a distribuição da quantidade e da qualidade da escolarização, de acordo com as necessidades e especificidades dos empregos, dos serviços, da produção, da circulação e consumo dos produtos. Determinadas pela economia, as escolas deveriam funcionar, em grandes traços, da seguinte maneira: para setores mais exigentes da economia transnacional, formação de elites intelectuais e profissionais capazes de estar em dia com as inovações da tecnologia; para postos de trabalho menos exigentes e que fazem parte da vida cotidiana da grande maioria dos membros de uma sociedade, bastaria capacitação quantitativa e qualitativamente suficiente e ajustada ao exercício profissional.

O que este texto vai defender com primazia é que a educação não pode reduzir-se a serviço do mercado e tampouco a democratização há de se limitar 
a expandir quantitativamente a escolarização tão somente para impulsionar o desenvolvimento econômico. É óbvio que a educação é essencial para o desenvolvimento da economia e esta é fundamental para a construção de uma sociedade forte e evoluída. Mas as finalidades da educação vão muito além da economia. $\mathrm{O}$ essencial neste aspecto é que a educação contribua para que o desenvolvimento da economia e da própria sociedade se proceda respeitando o princípio democrático do bem comum. Costuma haver muita distância entre princípio e realidade. É forçoso reconhecer que o valor moral de um princípio frequentemente se choca com variados e contraditórios interesses em disputa nos grupos humanos e dificilmente se realiza nas tramas do cotidiano social. De todo modo, não se pode esquecer que a educação busca a construção do presente e do futuro, e outra coisa não pode ser que a construção de um presente e de um futuro melhores para todos.

\section{BEM PÚBLICO E DIREITO SOCIAL: PRINCÍPIO E REALIDADE}

Educação é um bem público e direito social, pois tem como finalidade essencial a formação de sujeitos e, por consequência, o aprofundamento da cidadania e da democratização da sociedade. O conceito de bem público é aqui entendido como um princípio, isto é, como um imperativo moral que sobrepõe a dignidade humana aos interesses, inclinações e circunstâncias individuais. $\mathrm{O}$ individualismo corresponde ao entendimento de que os outros são meros meios para os interesses próprios. Diferentemente, o respeito à dignidade humana corresponde ao princípio que concebe o outro (e a humanidade) como fim, não meramente um meio. $\mathrm{O}$ respeito à dignidade humana justifica a prevalência do bem comum sobre as conveniências individuais. O público corresponde a uma concepção moral do bem comum. Trata-se de um valor moral, que mais comumente se situa nos planos dos ideais, mas muito escassamente é realizado na vida dos indivíduos e das sociedades, como tantos outros princípios. Embora pouco efetivamente praticado como valor moral, o princípio da prevalência do bem público sobre os interesses privados não deve perder sua centralidade nos projetos e estratégias de sociedades que buscam construir futuros mais felizes e mais justos.

Educação como bem público é essencial para a formação de cidadãos conscientes e, correlativa e inseparavelmente, de profissionais qualificados. Formação cidadã e capacitação profissional são aspectos co-essenciais, mutuamente referenciados e solidariamente constitutivos do sujeito social. Cidadãosprofissionais ética e tecnicamente responsáveis e qualificados são os principais 
atores do fortalecimento econômico e, inseparavelmente, do desenvolvimento da nação. Nessa concepção, a economia é uma dimensão essencial da vida humana, mas não é a razão de ser da sociedade. Ao contrário, é a sociedade, guiada pelo valor moral do bem comum, que a deve determinar.

Discutir a educação como bem público e, então, como direito social, faz parte do reconhecimento da grande responsabilidade que as Instituições de Educação Superior (IES) têm relativamente à formação ética, científica e técnica dos indivíduos no marco da construção da sociedade. Os fins da educação com sentido público estão referidos à formação de indivíduos sociais, cuja construção pessoal integral se insere no plano mais amplo da construção da sociedade e, em termos universais, da dignificação da humanidade.

Entre princípio e realidade pode ser grande a distância. A ideia, ou ideal, de edificação da humanidade como escopo da educação não se coaduna com a lógica da mercantilização da vida humana, em geral, nem da mercadorização da educação, em particular. É preciso refletir um pouco mais sobre esse tema, pois os sistemas de educação superior estão se tornando cada vez mais privatizados, e isso poderia produzir uma crescente mercadorização da formação e dos conhecimentos. Entretanto, cumpre alertar que mercadorização e privatização não são necessária e exatamente a mesma coisa. Condenável é a mercadorização da educação, isto é, a transformação da educação, assim como de muitas outras atividades humanas, em meros produtos comerciais, commodities sujeitas às leis e normas dos mercados. Instituições educativas privadas, nos termos amparados e exigidos pela Constituição nacional, são legítimas e necessárias, desde que, sob a autoridade superior do Estado, cumpram com qualidade os objetivos públicos que são da essência da educação.

Lamentavelmente, para muitas instituições privadas, sobretudo as mais recentemente criadas, a educação é primordial e quase exclusivamente um empreendimento em função de uma progressiva e ilimitada acumulação de capital econômico. Como tendência geral e ressalvadas poucas e boas exceções, além dos ganhos financeiros de seus proprietários, essas instituições contribuem quase exclusivamente para a intensificação do individualismo possessivo, pouco ou nada se lhes dando o respeito ao princípio da dignidade humana. Nesse caso, a educação é mercadoria, e não patrimônio público. O outro é visto quase somente como concorrente a ser vencido, e o conhecimento e a formação fazem parte somente dos processos de maximização dos lucros privados e da ideologia que confere primazia ao individual em detrimento do social.

Mas nem toda instituição educativa privada é mercantilista e trata o conhecimento como mera mercadoria. Afortunadamente, há muitas instituições não 
estatais, especialmente as que se incluem no que hoje se convencionou chamar de "terceiro setor" do "público não estatal", que cumprem bem os propósitos de socialização dos fins educativos e prestam importante colaboração ao Estado e à sociedade civil. Natureza jurídica, enquadramento administrativo, origem do financiamento, gratuidade ou não da matrícula são elementos importantes para se fazer as distinções entre público e privado, mas não dão conta da complexidade desse fenômeno. As concepções de público ou de privado têm muito mais a ver com as finalidades estabelecidas pela instituição educativa, explicitadas ou não, se predominantemente dotadas dos valores do bem coletivo ou primordialmente orientadas aos interesses individuais, e, coerentemente, com os processos que se instauram visando ao cumprimento desses objetivos.

Embora isso não seja uma exclusividade delas, é nas instituições mais identificadas com o sentido do bem comum que se produzem e se socializam partes significativas dos conhecimentos potencialmente capazes de dar respostas a muitos problemas contextuais, e é nelas que se forma importante parcela dos atores que terão grandes responsabilidades na construção da vida pública de uma nação. Isto já justifica insistir na tomada de posição inicial, reiteradamente afirmada ao longo das presentes argumentações: segundo o princípio do bem público, a educação não pode ser entendida como mercadoria, nem tampouco o sistema educativo poderia acolher as práticas exclusivamente mercantilistas e de acumulação de lucros. Esta afirmação de princípio, na contramão da crescente mercantilização, implica todas as instituições. Sejam propriedades privadas ou mantidas pelo poder público, as instituições educativas têm funções e finalidades públicas que não deveriam ser negligenciadas.

A defesa da educação superior como bem público vem sofrendo severos golpes desde as últimas décadas do século passado. O neoliberalismo se consolidou globalmente como cosmovisão que determina a racionalidade da sociedade. Com apoio ideológico e financeiro de organismos multilaterais foram formuladas e postas em prática várias estratégias de reforma da educação superior com o objetivo principal de aliviar a responsabilidade e a participação do financiamento público e alimentar a expansão das empresas privadas mercantilistas. Os argumentos mais comumente esgrimidos pelos defensores da privatização e da mercantilização, com a anuência dos governos, são bastante conhecidos em várias partes do mundo: as universidades são inoperantes, corporativistas, demasiadamente onerosas, resistem a prestar contas à sociedade, são avessas à accountability, não atendem às necessidades da indústria e da população em geral etc. Mesmo admitindo que nem tudo são flores nas instituições de educação superior e que mais e melhor elas poderiam fazer, como em todos os 
demais setores da vida social, não se pode deixar de reconhecer o lugar central que elas ocupam nas sociedades mais evoluídas.

Instituições privadas existem há muito tempo, no Brasil. Mas nos últimos decênios prolifera um tipo novo, com objetivos explícitos de mercado. A privatização de cunho mercantilista é o fenômeno mais robusto das transformações que vêm ocorrendo na educação superior brasileira. Ela acarreta mudanças conceituais importantes que não só alteram as formas organizacionais; tocam a essência mesma da educação, que se refere às missões e finalidades. Na linha da mercantilização da sociedade e da educação superior, a formação do sujeito autônomo e consciente de suas responsabilidades na construção da sociedade já não é o escopo mais amplamente reconhecido. O cidadão aí cedeu lugar ao consumidor, a solidariedade e a responsabilidade social perderam valor para a competitividade.

Na cosmovisão neoliberal, educar e formar tendem a ser, principalmente, prover aos consumidores da educação maior capacidade competitiva e maiores possibilidades de sucesso individual. Para isso, já não servem a pedagogia tradicional, nem as antigas formas organizativas; agora são requeridas lógicas de mercado para maximizar a produtividade e assegurar a sustentabilidade das instituições educativas transformadas em empresas, por meio da proliferação de mecanismos de venda de serviços, diversificação de provedores, critérios de custo-benefício, instâncias de captação de recursos externos, ampliação dos mecanismos de relação com as empresas etc.

O conhecimento efetivamente cria novas possibilidades de desenvolvimento para os indivíduos e para os países. Mas não se há de esquecer que, na vigente cosmovisão da sociedade da economia global, a produção, a aquisição, a distribuição e o uso dos conhecimentos estão predominantemente associados a interesses da maximização da competitividade das empresas, comumente supranacionais, e ao egocentrismo possessivo. Se assim é, não contribuem para a equidade, a isonomia e a qualidade de vida de todos os membros da sociedade.

Segundo as atuais tendências hegemônicas, a educação deve estar a serviço da produção e do consumo dos conhecimentos e das competências como estratégia de aumento da competitividade mercadológica, em detrimento da formação humana integral e da construção de sociedades democráticas. O educando se transforma em consumidor de um serviço educacional e de um produto - o conhecimento - e o cidadão é tratado como um recurso humano enredado na relação produção-consumo.

À inovação tecnocientífica, concebida como força motora do progresso, é dado lugar de destaque no mundo da produção intelectual e 
econômica. Para universidades, indústrias e governos, a inovação científica e tecnológica é a mola propulsora do desenvolvimento sustentável, do "progresso" e da inserção internacional dos países. Mas nem toda inovação que vige atualmente nas universidades e outras instituições de pesquisa se orienta por valores do bem viver público, solidário e ético. Em graus variáveis e em grande parte, a inovação, tal como praticada nessas instituições, costuma estar mais comprometida com a competitividade da economia de mercado que com o desenvolvimento igualitário da sociedade. Ela tem sido dominada por lógicas comerciais e financeiras e não pelos interesses do mundo do trabalho e da sociedade civil (PETRELLA, 2005 , p. 95). É mais propriamente mecanismo de competitividade que ferramenta social.

Aumentar a competitividade corresponde a ter sempre mais e mostrarse melhor que os outros, em detrimento dos valores da coletividade social. Essa inovação qual hoje pensada e praticada em algumas instituições acadêmicas de grande prestígio funciona, então, como motor da competitividade, tanto na relação capital-capital (capitalista contra seus concorrentes), como na engrenagem capital-trabalho (relação entre patrão e empregados). Por isso é bastante valorizada por empresários e por universitários simpáticos à ideologia que impõe à educação superior o papel essencial de contribuir para o aumento da competitividade do setor produtivo e da inserção ativa das empresas no mundo da economia globalizada. Em casos extremos, pouco valem os ideais da coesão social e da dignidade humana de todas as pessoas, mas muito valem o desenvolvimento das empresas e o aumento dos indicadores do produto interno bruto do país.

\section{RESPONSABILIDADE DO ESTADO E DA SOCIEDADE}

Um bem público é da esfera da solidariedade e da responsabilidade de todos, conformando o capital comum e imprescindível para a existência humana individual e coletiva. Sendo a educação e o conhecimento direitos humanos e sociais insubstituíveis e primordiais para a vida humana, somente os poderes públicos podem ser responsáveis por eles, em termos de regulamentação, legislação, supervisão, controle, proteção, avaliação etc. (PETRELLA 2005, p. 158). Mas a responsabilidade do Estado deve se dar em um contexto de solidariedade. Implica a participação da cidadania, isto é, de atores que assumem suas responsabilidades não somente por si, mas também pelo conjunto da sociedade. 
Lembra Petrella que a palavra solidariedade provém do latim solidus, princípio jurídico que indica que os membros de um grupo são responsáveis em conjunto pelas ações dos outros membros.

Um bem privado comercial é da esfera da competitividade e da exclusividade. Para que o privado seja assegurado como propriedade particular, é preciso excluir os possíveis concorrentes. A sociedade impregnada pela ideologia da competitividade tem em alto valor expressões como produtividade, eficiência, efetividade, controle, previsibilidade, gestão, empreendedorismo e outras da esfera da economia. A ideologia expressa por essas palavras-chave se extravasa das empresas e invade todas as dimensões da sociedade. Nas instituições educativas comprometidas com a ideologia da competitividade segundo os moldes empresariais, a formação passa a ter como valor central a produção do indivíduo-competidor e como horizonte a derrota dos demais concorrentes.

Os bens públicos, por serem parte essencial do direito que todos têm à vida digna e saudável, precisam ser universalmente acessíveis e não podem ser tomados como mercadoria. Ao Estado cumpre, entre outras responsabilidades, proteger e promover a educação e o conhecimento como bens públicos. Isto não exclui a legítima possibilidade de existir instituições educativas não estatais, e muitas delas prestam excelente colaboração para a construção de uma sociedade educada e de um sistema de conhecimentos importantes para a cidadania em geral. O importante aí é que essas instituições não privatizem o que por natureza é público, caso em que a formação e o conhecimento sejam oferecidos como produto de caráter privado e comercial e não como um direito humano e social imprescindível ao bem comum.

Enquanto os bens privados implicam competitividade e exclusão, os bens públicos se baseiam nos princípios de equidade, solidariedade e inclusão. Quando alguns indivíduos são proprietários de algum produto comercial, isso implica necessariamente que outros não o sejam; a apropriação de um bem privado se faz em contexto de competição. $O$ acesso de alguém a um bem público não exclui o direito de outros; pelo contrário, uma sociedade se enriquece à medida que mais cidadãos têm acesso aos bens públicos de qualidade. Sociedade bem constituída é a que é conformada por cidadãos cultos, capacitados e cônscios de suas responsabilidades sociais. A educação (incluindo os conceitos de formação humana integral e conhecimento) é essencial, por isso mesmo, primordial e insubstituível para a elevação do espírito humano e para o desenvolvimento da economia, esta enquanto estrutura e organização das condições materiais da sociedade. 
Há, então, uma distinção fundamental entre a educação-bem público e educação- mercadoria. Enquanto a primeira tem como referência central o aprofundamento do bem comum segundo valores da equidade e da igualdade democrática e social, a segunda tem seu foco no lucro do empresário e no desenvolvimento de uma sociedade competitiva e dominada pelo individualismo possessivo. Sociedade constituída por indivíduos que competem entre si pela posse de bens particulares é sociedade partida, injusta e violenta. Sociedade cimentada pela valorização dos valores sociais e pelo ideal do bem comum tende a ser mais coesa e fortalecida, embora jamais isenta de contradições e conflitos. Pensar a educação, o conhecimento, a formação humana integral como essenciais ao contexto do viver bem em sociedade, ou, ao menos do viver menos conflituoso, implica, então, reconhecer o importante papel das instituições educativas relativamente à formação dos jovens para a participação ativa na construção e na prática da imprescindível democracia e, inseparavelmente, da difícil paz.

Educação democrática implica expansão da cobertura, justiça social, qualidade científica e relevância social para todos. São exigências éticas e políticas que se requerem da educação pública, além de técnicas e científicas, pois são essenciais à construção de sujeitos sociais, à consolidação da sociedade democrática e dos processos de inclusão socioeconômica.

O Estado, com a colaboração da sociedade, tem o dever inescapável de prover a educação de qualidade para todos. Esta é uma condição importante para que a sociedade não seja tão partida e autofágica, ainda que se deva entender que muitos dos problemas estruturais da humanidade não podem ser solucionados pelas instituições e sistemas educativos. Muitos deles sequer foram criados pela educação, mais provável tenham sido maximizados pela falta de educação. Mas sem educação pública de qualidade, certamente os problemas humanos seriam muito mais graves.

Decorre do princípio da responsabilidade coletiva a importância da valorização social daqueles atores que têm grande centralidade na edificação de uma sociedade na qual todos tenham possibilidade de acesso ao conhecimento de valor público. De um modo especial, merecem reconhecimento e melhoria em seus processos de formação e de trabalho os professores de todos os níveis do sistema educativo e os pesquisadores vinculados às universidades e outras instituições do complexo de ciência e tecnologia. Um sistema educativo de qualidade, essencial para a construção de uma sociedade evoluída econômica, intelectual e eticamente, só pode existir se os atores responsáveis por sua consolidação tiverem boas condições de formação pedagógico-científica e de exercício profissional. 
A pesquisa básica da área de ciências duras, bem como os conhecimentos produzidos nas humanidades, que não possuem muitas vezes um valor imediato de mercado, mas certamente têm interesse público, precisam merecer atenção especial dos Estados com relação a financiamentos. Não é o que ocorre mais comumente. Prestígio e financiamento se vinculam às pesquisas que estão conectadas com a indústria e com o comércio, de acordo com a perspectiva de que os conhecimentos "úteis" e aplicáveis são os motores do desenvolvimento. Mas, lamentavelmente, essa conexão linear entre conhecimento e progresso vem descartando os objetivos humanísticos e culturais da sociedade e dos indivíduos (ALTBACH, 2008, p. 13).

A trajetória de escolarização fornece bases de conhecimentos, de valores e de organização dos processos formativos da construção jamais acabada dos sujeitos ao longo da vida. Isso carrega dois significados importantes. Primeiro, a educação deve ser entendida e realizada como um sistema; a melhoria quantitativa e qualitativa de um nível educacional está estreitamente vinculada à melhoria dos demais e do conjunto. Segundo, a exclusão escolar é uma das formas mais perversas de injustiça, pois priva os indivíduos e, por extensão, a sociedade dos fundamentos e ferramentas cognitivos, axiológicos e práticos essenciais para a edificação de uma vida digna e construtiva.

As instituições educativas, especialmente as universidades, são referências e centros fundamentais para a produção, o avanço e a elevação da vida intelectual da nação e da sociedade. Elas contribuem efetivamente com os esforços coletivos de construção dos bens públicos e comuns, por meio de conhecimentos. Por natureza, são instituições para o bem comum, embora claramente se possa perceber que muitas delas já perderam, em grande parte, esse sentido. Baseadas no princípio da equidade, as instituições educativas deveriam ter no marco de suas finalidades essenciais e de acordo com as condições e possibilidades de seu campo de atuação, o objetivo de contribuir para a minoração (idealmente, a erradicação) de desequilíbrios vigentes na cidadania. Em outras palavras, contribuir para o reconhecimento de que a dignidade humana socialmente construída deve sempre e em todas as circunstâncias prevalecer sobre os interesses privados das empresas.

\section{EQUIDADE E DEMOCRATIZAÇÃO DA EDUCAÇÃO SUPERIOR}

O princípio da equidade, que está na base de uma sociedade democrática, é um valor a ser realizado também nos processos ditos de democratização da educação superior. Mas a ampliação de matrículas e a expansão das condições 
de oferta são apenas uma face da chamada democratização da educação superior. A outra face essencial é a qualidade. Mais ainda: a educação precisa ter qualidade pública e social. Não é suficiente que seja boa e correta nos termos das exigências burocráticas, técnicas e científicas. É também imprescindível que contribua para a construção de um mundo melhor, isto é, um mundo mais educado, mais evoluído culturalmente e socialmente mais justo.

A crescente demanda por educação superior tem resultado num grande incremento de matrículas e, obviamente, de tipos diversificados de instituições. De um lado, esse fenômeno da expansão dos sistemas superiores, especialmente no que se refere ao acolhimento de importantes segmentos da população tradicionalmente excluída, corresponde a um legítimo projeto que busca diminuir, ainda que de forma muito restrita, as desigualdades sociais. Com isso ganham os indivíduos incluídos, que se beneficiam da educação para seu crescimento pessoal e uma inserção mais favorável no mundo do trabalho; e ganha a sociedade, que passa a incorporar mais gente com maior capacidade de participar construtivamente nas esferas públicas da vida social e política e nos âmbitos profissionais e econômicos da produção e do consumo.

Porém, não há só ganhos na ampliação da educação superior, embora os aspectos positivos superem em muito os negativos. Mais gente na educação superior é importante para a democratização, a coesão e a elevação intelectual e econômica de uma sociedade. Mas é preciso entender alguns limites desse fenômeno, não para justificar a inércia, porém, sim, para melhor fundamentar e coerir as ações propositivas. Os sistemas de educação superior e suas instituições se tornaram muito mais complexos, com a ampliação das matrículas, com a incorporação de novos contingentes de estudantes e professores e com a explosão dos conhecimentos e formas de produzi-los e disseminá-los. Essa complexificação traz novos problemas de ensino, organização e gestão, mas, longe de ser um empobrecimento, representa um enriquecimento do sistema e um aumento da qualidade social da educação superior em vista de seus compromissos com a democracia e equidade.

O fenômeno da massificação tem trazido inevitavelmente muitos problemas que as diferentes instâncias da educação superior, em níveis mundiais, nacionais e institucionais, não estão conseguindo resolver a contento, tanto em termos estruturais como de qualidade pedagógico-científica. As instituições e os sistemas de educação superior estão se tornando crescentemente mais complexos e diversificados. A população estudantil de educação superior se compõe de indivíduos provenientes de grupos sociais muito diferenciados, incorporando crescentemente jovens de famílias de baixa renda e portadores de escasso 
capital cultural e familiar. Em consequência, suas trajetórias acadêmicas são constantemente ameaçadas por riscos de insucesso, de interrupção e de evasão. Esse novo cenário da educação superior impõe a necessidade de as instituições compreenderem os impactos que os novos contingentes de estudantes produzem no cotidiano universitário. Necessário que as instituições repensem seus novos papéis frente ao conjunto de demandas que a sociedade lhes determina cumprir.

Do ponto de vista dos estudantes, muitas são as dificuldades. Para alcançar alguma mobilidade social ascendente por meio da educação, os jovens com maiores carências econômicas e sociais, geralmente os primeiros da família a chegar a um curso superior, precisam esforçar-se muito para superar a quantidade e a qualidade dos conhecimentos escolares adquiridos por seus pais. Caso contrário, não conseguirão competir com os jovens mais ricos nas duras disputas por empregos que sejam compatíveis com seus estudos e com suas aspirações. As dificuldades são maiores em países pobres e em vias de desenvolvimento. Eles estão desenvolvendo várias estratégias para aumentar o acesso, mas ainda não alcançaram satisfatoriamente os objetivos de plena cobertura, qualidade e igualdade. Por sua vez, os países mais ricos não apresentam problemas de acesso, mas também não resolveram a questão da igualdade (ALTBACH, 2008, p. 7).

Importante dificuldade advém do despreparo institucional, notadamente da precária formação didático-pedagógica dos professores. A forçada improvisação de professores, de currículos e de infraestrutura física tem comprometido o sentido público da educação superior em ao menos dois aspectos fundamentais. Em primeiro lugar, o caráter público da educação requer necessariamente a realização efetiva do princípio da equidade com elevada qualidade para todos e isto está muito longe de ser atingido no Brasil. Segundo, a oferta de uma educação de escassa qualidade, ainda que alcançando contingentes mais amplos, também pode estar contribuindo para a permanência e até mesmo pelo aumento da segmentação dos diferentes estratos sociais.

Embora se reconheça haver sérios limites na ampliação do acesso à educação superior, muito mais injusto e pernicioso é o elitismo que marginalizou a esmagadora maioria dos jovens ao longo da história brasileira. É verdade que a escolarização não é garantia plena de indivíduos e sociedades mais bem realizados. Mas a falta de escolarização produz mais pobreza. Os jovens que, driblando seu histórico pessoal de vulnerabilidade econômica, e, ainda que apresentando baixos repertórios culturais, conseguem frequentar um curso de nível superior poderão se beneficiar de maiores ganhos salariais, melhores condições de vida, mobilidade social e elevação da autoestima. 
São de mútuas implicações as relações entre o econômico e o simbólico, ou seja, entre economia e a cultura, os conhecimentos, as ideologias. Resultam dessas relações as hierarquias profissionais e as correspondentes atribuição e distribuição de poderes e prestígios que vigem nas divisões sociais. Dada a importância da educação superior nessas relações entre o econômico e o simbólico, já que hoje o conhecimento é criado e distribuído principalmente para alavancar o progresso das empresas e os ganhos do sistema financeiro, ela desempenha destacados papéis na configuração de uma sociedade. Tais papéis não são unívocos e unidirecionais. São contraditórios e complexos. Reforçam determinados valores, certas ideologias e alguns interesses em detrimento de outros contraditórios, opostos ou diferentes. Tudo isso é de enorme relevância para os homens de hoje e de amanhã, pois são escolhas entre elevar as condições e estruturas de humanização da sociedade ou aderir à antiética mercantilização da vida que vem sendo produzida pela economia de mercado.

Todos os esforços de ampliar o acesso à educação superior são importantes passos na direção da isonomia social, mas, isoladamente, não conseguem superar por completo as brechas e oposições de uma sociedade historicamente hierarquizada. Isto porque a educação, e o mesmo se diga do conhecimento, está estruturalmente ligada ao complexo econômico e simbólico que constitui uma sociedade concreta. Se o conhecimento e a formação não se constituem rigorosamente como patrimônio social e, ao contrário, se submetem aos padrões de produção e distribuição destinados à expansão das capacidades de ações competitivas, a sociedade que eles ajudam a conformar continuará essencialmente dividida, em distintos e mutáveis níveis, entre excluídos e incluídos

Junto com a multissecular exclusão econômica e social se vai constituindo no imaginário das famílias e dos jovens de baixa renda e escassos capitais culturais a ideologia da naturalização da exclusão, que, por sua vez, produz em termos práticos a autoexclusão. Como a sociedade e o Estado capitalistas erigem como referências centrais para toda a população os valores e, notadamente, os interesses dos círculos mais ricos, se naturalizam as desigualdades e os espaços que a cada um caberia ocupar nas estruturas hierarquizadas. A exclusão se completa pela autoexclusão, isto é, pela internalização da ideologia segundo a qual a exclusão não é histórica e socialmente produzida e que, para muitos, é natural ser excluído. Mas é ainda necessário acrescentar que a exclusão e a percepção da exclusão têm várias causas, distintos matizes, diversos níveis e diferentes consequências. Compõem esse fenômeno diferentes e interligadas coisas, como carências econômicas e culturais, analfabetismo em diferentes graus, escassas condições de escolarização, distanciamento entre escola e em- 
prego, currículos inadequados, falta de motivação e de perspectivas de futuro, repetência, evasão etc.

Assim se vai criando no imaginário coletivo e na percepção individual de muitos jovens das camadas mais pobres a ideia de que são naturais suas baixas capacidades competitivas e que os cursos mais exigentes e de maior prestígio econômico e social se reservam aos mais ricos. Aos mais pobres está quanto muito facultado o acesso a cursos escassamente considerados nas hierarquias acadêmicas e que levariam a empregos de menor prestígio econômico e social. Essa forma de exclusão, a exclusão por dentro do sistema escolar, que muitas vezes ocorre como uma autoexclusão, não transparece nas estatísticas e nos discursos políticos dos ganhos da democratização educativa. São questões que se colocam à educação, mas que fazem parte de todo um histórico de injustiças sociais.

A democratização da educação, entendida como indução da expansão do acesso e aumento da matrícula estudantil, apresenta um grande valor como política de inclusão de grupos historicamente marginalizados. Porém, a democratização não deveria limitar-se à expansão do acesso a cursos de graduação, sem preocupar-se efetivamente com a qualidade da formação e dos conhecimentos. Se a oferta educativa é de baixa qualidade e as condições de permanência são precárias, ocorre uma "democratização excludente". Essa expressão, provocadora e paradoxal, serve para recuperar o argumento de que todos, independente de sua condição social e econômica, têm direito não a qualquer educação, mas sim a uma educação de qualidade.

Uma educação de baixa qualidade para as camadas populacionais mais pobres e culturalmente mais carentes, ainda que com ampla cobertura, não cumpre totalmente o princípio da equidade e, portanto, não contribui plenamente para a construção de uma sociedade justa e evoluída. Certamente uma educação de baixa qualidade é melhor que nenhuma educação, uma vez que, ainda que escassamente, contribui para melhorar um pouco as condições de vida dos indivíduos e para aumentar o cabedal de conhecimentos e de competências profissionais úteis ao desenvolvimento da nação. Em outras palavras: se bem que melhora alguns indicadores sociais, uma educação de baixa qualidade também contribui com baixa qualidade para a construção da justiça social e para a diminuição dos desequilíbrios entre pobres e ricos, incluídos e excluídos.

Estudantes pertencentes a estratos sociais mais baixos, em geral, receberam uma insatisfatória formação escolar nos níveis precedentes; por isso, quando chegam à educação superior se encontram em desvantagem em relação aos jovens que puderam construir um percurso formativo mais ajustado às exigências e dinâmicas da sociedade de economia global. 


\section{DESIGUALDADE E EDUCAÇÃO PÚBLICA}

Há uma forte correlação entre pobreza e baixa escolaridade. Os precários indicadores de escolarização são um dos aspectos do grave quadro de desigualdades e de falta de equidade ainda vigentes na sociedade brasileira. É justo reconhecer que importantes segmentos sociais vêm alcançando uma certa ascensão social, nos últimos anos, mas ainda remanescem grandes assimetrias acumuladas ao longo da história brasileira. A Pesquisa Nacional por Amostragem Domiciliar (PNAD/2008) informa que os 10\% mais ricos são proprietários de $43 \%$ da riqueza do país, enquanto que os $50 \%$ mais pobres detêm apenas $18 \%$ dessa riqueza. Essa assimetria social e econômica é uma das maiores do mundo todo.

Por conseguinte, o desequilíbrio também acontece na escolarização, tanto em aspectos quantitativos como qualitativos. Em termos gerais, os indicadores não são nada bons. Em média, os brasileiros não chegam a completar sete anos de escolaridade, isto é, não concluem a educação básica. Quando esmiuçados, esses números podem pôr de manifesto alguns outros dados dos desequilíbrios sociais. Os segmentos sociais mais ricos têm o dobro do tempo de estudos dos mais pobres: respectivamente, mais de 10 anos contra cinco anos. No nordeste, região que apresenta altos índices de pobreza, somente $1 / 5$ das crianças completa a educação básica.

No ensino superior, o aumento de matrículas que vem ocorrendo mais notadamente nos últimos quinze anos ainda está muito abaixo da meta estabelecida pelo Plano Nacional de Educação (PNE) para o final da década passada. A meta era atingir, até 2010, a taxa de matrícula em educação superior de $30 \%$ dos jovens entre 18 e 24 anos. Apenas a metade dessa meta foi alcançada. Houve, nesse período, grande expansão de instituições, algumas públicas e a maioria, privadas, foram criados vários programas de ações afirmativas visando a acolher e/ou beneficiar contingentes de jovens pertencentes a grupos sociais tradicionalmente desfavorecidos, mas, por várias razões, sobretudo econômicas, ainda estão fora da educação superior cerca de $85 \%$ dos jovens da faixa etária adequada.

A pobreza é uma das causas mais importantes da exclusão educacional e dos limites dos projetos e programas que objetivam ampliar a escolarização. Segundo o IBGE, por pobres, $25 \%$ dos jovens da coorte entre 18 e 24 anos não teriam condições de frequentar um curso superior mesmo que esse fosse totalmente gratuito. Não deve causar surpresa o dado revelado pela PNAD/IBGE/2007 e que mostra ser o passivo educacional ainda maior que o econômico: enquanto $30,2 \%$ das famílias brasileiras pertenciam, nesse ano, ao quintil mais pobre, 
apenas 3\% dos jovens desse mesmo estrato estavam matriculados em educação superior. São os afrodescendentes, pobres em sua maioria, as grandes vítimas dessa perversidade. Embora esse grupo constitua aproximadamente a metade da população brasileira, considerados os pretos e pardos, segundo designação do IBGE, apenas $25,4 \%$ dos estudantes de cursos superiores são negros (menos de $3 \%$ ) ou pardos.

Ainda há no país 14 milhões de adultos analfabetos, sem contar o analfabetismo funcional e o digital. A propósito, pouco mais de 1/3 das famílias têm computador em casa, mas aí também se constata uma distribuição muito desigual: possuem algum tipo de computador mais de $92 \%$ das residências cujos moradores acumulam acima de 20 salários mínimos, contra pouco mais de 1/4 das casas cujos residentes ganham menos de 10 salários mínimos. Eis aí outro tipo de exclusão, com forte impacto nas competições por empregos e no campo social. Essa desigualdade tem nome: inforricos e infopobres, valendo isso para países e para indivíduos.

Por incapacidade de prover seus estudos com recursos próprios, pela baixa atratividade do mundo do trabalho em termos de oferta de bons empregos, por desmotivação e baixa qualidade nos processos de ensino-aprendizagem gerados nos anos precedentes, ou por muitos outros motivos, o fato é que existe, no sistema superior brasileiro, uma enorme quantidade de vagas não preenchidas, beirando quase 1 milhão e meio, $98 \%$ delas no setor privado. Dizendo de outra maneira: do ponto de vista linear e quantitativo, há mais oferta nos cursos superiores que demanda por parte de concluintes do ensino médio, mesmo por que somente 30\% deles ingressam em alguma IES. Além disso, com esmagadora predominância nas instituições privadas, $25 \%$ dos estudantes não concluem seus cursos superiores.

Há ainda um outro fator que deve ser levado em conta nas discussões sobre a democratização da educação superior e a ampliação do acesso a seus cursos. No Brasil, atualmente, quase $90 \%$ das instituições superiores pertencem ao segmento privado. Mais importante ainda é considerar que $48 \%$ dessas instituições têm fins de lucro, isto é, são instituições particulares de natureza comercial e sujeitas à legislação mercantil. Dessa maneira, nelas, o valor dinheiro provavelmente afasta outras expectativas de caráter social e de interesse público. E embora o setor público tenha crescido, é nas IES particulares e com finalidade lucrativa que está ocorrendo a maior expansão.

O efeito da educação superior sobre as perspectivas econômicas e sociais, especialmente na questão da renda dos trabalhadores e na expectativa de obtenção de emprego, é amplamente reconhecido. Um diploma universitário, no 
Brasil, pode aumentar a renda em $150 \%$ ou mesmo, em casos excepcionais, em até $164 \%$, em comparação com empregados que tenham somente o ensino médio, segundo estudo da OCDE divulgado no relatório "Education at a Glance" em setembro de 2011. Enquanto 77,4\% dos empregados completaram o ensino médio, a taxa de empregos de quem tem nível superior é de $85,6 \%$, segundo a OCDE.

Esses dados sugerem que há motivações importantes, mas, também, sérios limites nos intentos de democratização da educação superior. Indicam, além disso, que as questões aí concernidas não são apenas quantitativas, mas também qualitativas. Há questões relacionadas à economia e, então, ao social e ao ideológico. Não cabe apenas à educação superá-las. Tampouco é possível, somente pela via escolar, resolver os mais graves problemas estruturais de uma sociedade hierarquizada e partida pelas desigualdades. É bem verdade que a educação escolar pode ser um fundamental instrumento de democratização e, portanto, de inclusão e diminuição de desequilíbrios sociais. Por outro lado, ela também pode contribuir para a preservação e fortalecimento dos interesses dos segmentos mais poderosos e, então, aprofundamento das assimetrias sociais.

As limitações relativas ao financiamento da educação não se restringem aos indivíduos e famílias de baixo poder aquisitivo. Também o Estado tem severas restrições orçamentárias para oferecer educação gratuita e pública em todos os níveis e de boa qualidade a todos que a demandam. Por mais que crie programas de expansão da cobertura, eles serão sempre insuficientes. É o caso dos programas de ações afirmativas em que o Estado financia, em instituições privadas, total ou parcialmente, os custos das mensalidades de estudantes pobres. De um lado, são importantes ações políticas para o Estado que as formula e as pratica. Por outro lado, são bem-vindas para as instituições privadas que cumprem as exigências, pois, aumentam seu faturamento por meio de mensalidades de estudantes que não teriam recursos próprios para frequentar um curso superior. São importantes porque ajudam a democratização da educação superior, incluindo milhares de indivíduos econômica e socialmente vulneráveis, mas, isoladas e pontuais, ainda são incapazes de atacar com a força e a sustentabilidade necessárias os problemas centrais e estruturais da sociedade brasileira historicamente desigual.

Do ponto de vista da equidade, uma sociedade que não atende as necessidades educacionais, em quantidade e qualidade, de toda a população é injusta e democraticamente pouco desenvolvida. A educação de elite e para uma elite cumpre seu papel com relação ao mercado global e à preservação das classes 
ricas e poderosas, mas não contribui para a edificação de uma nação justa, ética e culturalmente evoluída.

Educação pertence à esfera da responsabilidade coletiva. Estado e sociedade não podem abdicar dessa responsabilidade. Se o Estado não tem recursos suficientes para atender a toda a demanda educacional, em quantidade e qualidade, setores da sociedade deveriam assumir essa responsabilidade com os devidos compromissos de cumpri-la segundo a ética do bem comum. Portanto, com os valores que fundamentam a formação humana integral e a consolidação de nações democráticas e econômica e culturalmente desenvolvidas. Muitos dos grandes empresários brasileiros se beneficiaram de uma formação técnicoprofissional em instituições de educação superior públicas e bem fariam se contribuíssem, agora, para o fortalecimento dessas instituições, com recursos financeiros, experiência e conhecimentos. Isso ajudaria as instituições a cumprir melhor suas responsabilidades públicas; dentre outras coisas, a dedicar-se mais intensamente às ações afirmativas no tocante ao acesso de grupos socialmente vulneráveis, à formação de professores, à melhoria qualitativa dos níveis precedentes e ao desenvolvimento de tecnologias sociais de interesse dos pequenos produtores e das camadas de baixa renda, em geral.

Na contramão das tendências atuais no sistema de educação superior brasileira, é preciso que a expansão da educação superior se dê prioritariamente pela via pública, especialmente num país cuja população ainda apresenta altas taxas de pobreza. Educação como bem público e direito social é um princípio cuja efetivação encontra sérias limitações de caráter econômico e político-ideológico, mas isso não é desculpa para não buscar realizá-lo, com todas as forças e por diversos meios. Mas a sociedade também presta uma grande contribuição por meio daquelas instituições educativas privadas que cumprem as exigências de qualidade e pertinência social estabelecidas pelo Estado e requeridas pela própria sociedade.

O importante é que a educação superior oferecida pelas instituições de educação superior públicas e privadas não seja um instrumento a mais a reforçar a invasiva mentalidade mercantilista que grassa na sociedade atual, nem tampouco seja um serviço e um produto que beneficiam apenas aqueles que podem comprá-los, para uso próprio.

\section{CONSIDERAÇÕES FINAIS}

O princípio da equidade determina o imperativo ético de diminuir ao máximo as desigualdades sociais. A progressiva diminuição das assimetrias na sociedade 
toda em boa parte depende da democratização da educação. Por isso, todo indivíduo tem direito a uma educação de qualidade e o Estado democrático tem o dever de assegurar que seja efetivada a educação de qualidade amplamente disponível. Esse princípio se insere na esfera dos direitos públicos e sociais e diz respeito ao desenvolvimento do processo de construção da autonomia pessoal, da cidadania, da profissionalização e, por extensão, da sociedade democrática. O conhecimento é mais que nunca a principal matéria prima do desenvolvimento econômico. Também a partir desse pressuposto nenhum Estado poderá escapar das necessidades de estender a toda a população os meios de adquirir mais conhecimentos e participar dos benefícios dos bens culturais em geral. Esse é um imperativo político e também econômico.

Da mesma forma que não se pode aceitar a crença do progresso infinito produzido pela ciência, também não se há de crer que se vai resolver a problemática da pobreza e das injustiças sociais somente pela ampliação das matrículas em educação superior. Mas o argumento das mudanças estruturais de largo alcance e longo prazo não pode servir de desculpas para nada fazer de imediato, mesmo que as ações sejam limitadas e insuficientes.

Ampliar a massa de conhecimentos da população é um imperativo que vale tanto para os indivíduos em termos da formação pessoal e cidadã, como no que se refere à capacitação profissional, pois tudo isso é fundamental para elevar os níveis de qualidade de vida das pessoas, fortalecer a economia e aprofundar os valores da democracia, na sociedade e na nação. Uma sociedade que não consegue, ou não quer, estender os benefícios da escolarização de boa qualidade a todos, além de estar condenada ao empobrecimento crescente no sistema mundial de alta competitividade, é também uma sociedade perversa. A falta de conhecimentos produz rejeitos. Quem não consegue produzir e consumir, por ignorância ou pobreza, é descartado, igual a um produto imperfeito, indesejável, inútil, incômodo.

\section{REFERÊNCIAS}

ALTBACH, Philip G. Funciones complejas de las universidades en la era de la globalización. In: LA EDUCACIÓN superior en el mundo 3. Educación Superior: Nuevos Retos y Roles Emergentes para el Desarrollo Humano y Social. Madrid: GUNI (Global University Network for Innovatión, Ediciones Mundi-Prensa, 2008. 
BRASIL. Instituto Brasileiro de Geografia e Estatística (IBGE). Pesquisa nacional por amostragem domiciliar. Brasília, 2008.

PETRELLA, Ricardo. El derecho a soñar. Propuestas para una sociedad más humana. Barcelona: Intermón Oxfam, 2005. 